\title{
EXPERIENCIAS ESCOLARES-COMUNITARIAS Y ETNICIDAD EN UNA COMUNIDAD MOCOVI DE ARGENTINA
}

\section{EXPERIÊNCIAS ESCOLARES-COMUNITÁRIAS E ETNICIDADE EM UMA COMUNIDADE MOCOVÍ DA ARGENTINA}

María Eugenia Martínez Universidade Nacional do Litoral - UNL

\section{Resumen}

El presente artículo recupera una de las experiencias de campo con un grupo socio étnico, que forma parte de la investigación doctoral sobre políticas y prácticas educativas de atención a la diversidad/inclusión educativa concretado entre el 2007-2013 en Argentina. Puntualmente, nos interesa abordar las reconfiguraciones de la etnicidad a partir de experiencias escolarescomunitarias en una comunidad Mocoví de la provincia de Santa Fe. Entendiendo a la etnicidad como la dimensión ideológica en el entramado de los procesos sócioétnicos identitarios (VÁZQUEZ, 2000). Durante el trabajo de campo pudimos documentar, a través de entrevistas en profundidad, observaciones participantes y análisis de diseños curriculares los conocimientos, valores y tradiciones que forman parte de la etnicidad y orientan la lucha etnopolítica de esta comunidad, como son: la organización comunitaria colectiva, el respeto por la naturaleza, la reconstrucción de la lengua, entre otros. A su vez, pudimos advertir como la etnicidad se iba articulando en la trama escolar-comunitaria.

Palabras claves: Etnicidad. Procesos socioétnicos y identitarios. Etnopolítica. 


\section{Resumo}

O presente artigo recupera uma das experiências de campo com um grupo socioétnico o qual forma parte da pesquisa Doutoral sobre políticas e práticas educativas de atender à diversidade/inclusão educativa concretizado entre os anos 2007-2013 na Argentina. Propriamente, interessa-nos abordar as reconfigurações da etnicidade a partir de experiências escolares-comunitárias em uma comunidade Mocoví do estado de Santa Fe. Entendendo à etnicidade como a dimensão ideológica em uma rede dos processos sócioétnicos identitários (VÁZQUEZ, 2000). No decurso do trabalho de campo pudemos documentar, através de entrevistas em profundidade, observações participantes e análises de desenhos curriculares; os conhecimentos, valores e tradições que formam parte da etnicidade e orientam à luta etnopolítica desta comunidade as quais são: a organização comunitária coletiva, o respeito pela natureza, a reconstrução da língua, entre outros. Por sua vez, pudemos advertir como a etnicidade ia se articulando no enredo escolar-comunitário.

Palavras-chave: Etnicidade. Processos sócioétnicos e identitários. Etnopolítica.

\section{Introducción}

El siguiente escrito retoma uno de los aspectos centrales abordados en la Tesis Doctoral sobre las Políticas y prácticas educativas de atención a la diversidad/inclusión educativa entre el 2007-2013 a partir de dos experiencias escolares diferentes en la Provincia de Santa Fe. En esta oportunidad nos interesa retomar, la dimensión de la reconfiguración de etnicidad en experiencias escolar-comunitarias del grupo socioétnico Mocoví de la provincia de Santa Fe Argentina.

Para el abordaje de este estudio se elige como sustento metodológico, el enfoque socioantropológico propuesto por Achilli (2005). El mismo se centra en tres núcleos problemáticos: 1) El conocimiento de la cotidianeidad social desde una perspectiva crítica recuperando los análisis de Heller y Kosik; 2) La mirada en los sujetos sociales sus representaciones y construcciones de sentido y 3) La dialéctica entre el trabajo de campo y el trabajo conceptual. En este punto, las herramientas son de la metodología cualitativa, trabajo 
de campo participante e intensivo desde observaciones, entrevistas abiertas en profundidad, análisis de material de archivo y normativas.

Como núcleo conceptual y transversal de esta problemática de investigación recuperamos el aporte de Vázquez respecto a los "procesos étnicos identitarios" (VÁZQUEZ, 2000, p.66) para dar cuenta de diversos niveles de análisis que permitan entender la constitución de los mismos en su dinámica cotidiana. Según este autor, pueden diferenciarse un primer nivel que focalice las particularidades socio culturales en la formación políticaideológica que se manifiesta como etnicidad; un nivel intermedio que distingue las identificaciones étnicas surpracomunitarias al interior de una red de relaciones socioculturales, que trasciende el concepto geográfico de región y se vincula a la identificación con grupos domésticos de las zonas de las que emigraron y nivel de las relaciones cotidianas, que refiere a la configuración de "identidades" socioétnicas del conjunto de grupos domésticos, dentro del marco de un campo de interacción socioétnico. Este campo es expresado a modo de zona de fricciones entre diferentes grupos étnicos diferenciados, cuyos modos de relación se sustentan en la dinámica de tensiones y contradicciones, a partir de las cuales el establecimiento de un grupo sobre otro genera una situación de dominio/subalternidad.

La dinámica de conformación de los procesos socio-étnicos identitarios destacan los aspectos simbólicos, lo(s) cuales se encuentran articulados a los modos de reproducción económico social.

Los análisis respecto a la "etnicidad", implican la consideración de las relaciones entre diversos grupos (socio) culturales, dentro de los límites de un mismo marco social, adquiriendo ambos, la condición desigual de grupo mayoritario y minoría.

La desigualdad en esta relación implica tener presente dos dimensiones que posibilitan la formación de la etnicidad, una se refiere a la construcción política que forman los organismos del Estado, las organizaciones étnicas mayoritarias y los medios de comunicación y desde el otro lugar, la apropiación de los aspectos legales por parte de las agrupaciones indianistas a modo de proyecto etnopolítico (VAZQUES, 2000).

Cabe destacar que otros antropólogos, también, abordan a la "etnicidad" como un proceso complejo, que expresa la dimensión ideológico-política dentro de los marcos de 
relaciones identitarias, las cuales forman parte de relaciones de clases (BALAZOTE y RADOVICH, 1999; ACHILLI 2010; ESCOLAR, 2007; RINGUELET 1992; GOROSITO KRAMER, 1992, entre otros) de ahí su carácter relacional y contradictorio.

\section{La configuración de la comunidad Mocoví en Recreo}

Si bien, la formación de la comunidad Mocoví en Recreo y su consolidación es reconocida por sus miembros entre los años 1988/1990, como un proceso que abarca desde las primeras reuniones hasta su organización "formal”, es decir, como Asociación civil.

El relato de esta historia tiene las huellas de un pasado profundo que se inaugura con la colonización de América y continúa con la relación entre el Estado/Nación Argentina y los Pueblos Indígenas desde su constitución, vinculación que ha estado signada por una tensión entre la invisibilización de las políticas públicas y la "puesta esporádica en escena" de los modos de vida de los diferentes Pueblos Indígenas de la nación.

En este sentido, la historia del pueblo Mocoví se inscribe en procesos sociohistóricos generales que remiten al entramado Estado/Pueblos Indígenas, a la vez que, adquiere las particularidades de esta relación en la provincia de Santa Fe.

Dentro de las peculiaridades del entramado entre el Estado y los Pueblos Indígenas en la provincia de Santa Fe, específicamente con el pueblo Mocoví, nos encontramos con determinados motivos claves que confluyen en la dificultad de la reconstitución histórica de diferentes períodos que se vinculan con las formas de enseñar su propia histórica, por parte de los Mocovíes, que tiene a la tradición oral y la transmisión familiar como vehículos centrales; asociado con esto, las estrategias de negación de la identidad, como lo destacara uno de sus miembros, producto de las políticas de exterminio e invisibilización estatales.

Antes del período de colonización, los Mocovíes integraban la familia linguiística Guaycurú junto con los Tobas, Pilagás, Kadiweu, Payagúa, Mbayá y Abipón, el hábitat de estos grupos estaba en lo que era denominado como Gran Chaco, específicamente, en el Chaco austral (comprendido entre Chaco y Santa Fe) junto con los Abipones (GUALDIERI, 2004).

Su forma de organización socioeconómica y política tenía como eje la caza, la recolección y el semi-nomadismo; su base nuclear era la familia que, a su vez, se articulaba 
con otras, bajo la coordinación de un líder por clan o grupo tribal y de "Caicek" general de toda la comunidad.

“...La palabra cacique en realidad no sé qué quiere decir, de quien es la palabra no sé pero nosotros teníamos a la persona que dirigía a una comunidad o a un pueblo le decíamos Caicek que era como ¿vio usted lo que se le pone a los animales?, sería como un bozal, yo lo veo con los toros o con los caballos y con ese bozal se lo domina (...) se le coloca al animal, justamente, para hacerlo entender para donde tiene que caminar (...)

(...) y después estaban los líderes que lideraban el clan familiar, un grupo grande de familiares donde estaban los hermanos, los tíos, los yernos, todos, esos clanes tenían un líder que era el vocero de esa gran familia, en una comunidad podía haber cuatro o cinco grupos tribales que tenían su propio líder que eran los que hablaban con el cacique; ellos eran los que tenían que ir conectando a toda la comunidad, tomando decisiones en conjunto con el cacique; cuando surgía un problema eran los que tenían que solucionar en conjunto todos los problemas de la comunidad y que todavía eso se manifiesta hoy en día, todavía no se ha podido quebrar(...) antes se imponía a un cacique por su gran sabiduría y por gran capacidad de dirigir, de convencimiento(...) el cacique tenía un gran poder de convencimiento y de tratar a las personas era el que estaba continuamente viendo las cuestiones de todas las familias; era el más sabio por eso se lo dejaba como el cacique general..."(ANTONIO, miembro de la comunidad. Registro de campo №25. Entrevista personal. Julio 2009 en MARTÍNEZ, 2014 pp 194 Políticas educativas y Diversidad sociocultural. Un estudio socioantropológico sobre la construcción de políticas y prácticas educativas acerca de la atención a la diversidad, tesis doctoral en Humanidades y Artes mención Antropologìa, UNR. Sante0 Fe. Mimeo).

La historia del pueblo Mocoví está atravesada por procesos conflictivos respecto a la relación con quienes detentaba el poder económico, político e ideológico de la región, que se inicia con la etapa de la colonización y presenta una continuidad respecto al vínculo dominación/legitimación, provocando marcadas transformaciones en los modos de vida del pueblo.

Diferentes dispositivos se desplegaron para el sostenimiento de esta relación; entre ellos, nos encontramos con: campañas militares, misiones y reducciones que fueron claves para los procesos de disciplinamiento y que tuvieron diferentes matices de acuerdo a los intereses regionales.

Para la zona santafesina, las campañas militares tenían como objetivo la expansión de fronteras a través del exterminio de caciques y "rebeldes" y la inclusión gradual de la Revista RBBA $\mid$ Revista Binacional Brasil Argentina 
población indígena a las denominadas "reducciones" y misiones, las cuales, tenían a la escuela y la iglesia como instituciones canalizadoras de los intereses dominantes, bajo la consigna de la enseñanza de pautas "civilizatorias" que estaban directamente asociada a procesos de dominación ideológico-cultural, desde la imposición como saberes legítimos, de los principios religiosos, el cambio de hábitos cotidianos y el aprendizaje de una agricultura de subsistencia y trabajo doméstico.

“...Tanto durante la época colonial como la republicana existía la preocupación de contener a los indígenas e incorporarlos a la sociedad hegemónica, para lo cual se fundaron las misiones religiosas y reducciones que, además de su rol evangelizador, cumplieron un papel importante en este sentido. A media dos del siglo XVIII, la conversión de los indígenas a las pautas culturales occidentales estuvo en manos de los misioneros de la compañía de Jesús..." (GRECA, 2009, p.3).

Una vez lograda la etapa de las misiones y "reducciones" la población indígena era destinada o a la defensa de la frontera o declaradas "personas libres", con el principal objetivo de la ocupación de tierras para el despliegue de las "nuevas pautas de vida aprendidas".

Durante el siglo XIX, los cambios se centraron en la formación del Estado-Nación en Argentina y la consolidación de las clases sociales, integrados al mercado internacional. Las economías provinciales iban entramándose en este modelo económico-político agroexportador que para esta región significaba la apuesta a la producción cerealera, ganadera, la industria y la red ferroviaria.

En esta coyuntura, confluyen dos procesos que tenían como centro la continuidad con las transformaciones en la reproducción de la vida cotidiana de las poblaciones indígenas, de la cual, la provincia de Santa Fe no estuvo ausente, y tenía como actores principales a la Iglesia católica y a las políticas estatales, a través del proyecto económico-político liberal, bajo las ideas de "orden y progreso".

Los mecanismos para concretar dichas transformaciones, eran a partir de campañas militares con el doble objetivo de la apropiación de territorios propicios para el desarrollo productivo y la búsqueda de mano de obra (obreros asalariados) propias de las relaciones capitalistas que se iban consolidando.

La lucha política de este pueblo, pese a tener una ausencia en la "historiografía oficial", se fue construyendo de diferentes formas a lo largo de la historia y tuvo a las 
familias, a través de la transmisión oral, como vehículos centrales; aún, con relatos sutiles que dejaban como significante la importancia de recordar los modos de vidas de los Mocovíes:

“...Mi papá vivió la parte de vida cuando todavía ellos vivían en las islas, los montes que todavía eran perseguidos por la policía porque ellos decían que cuando ellos eran chicos y los encontraban pasando por un campo, los corrían a caballo los corrían con los látigos; entonces, cuando él llega a grande dice no soy de esos que estaban siendo perseguidos, arma una estrategia de vida, la estrategia era negar la identidad para no sufrir eso..." (ANTONIO. Referente de la comunidad. Registro de campo $\mathrm{N}^{\circ} 34$ Encuentro colectivo "Los significados de la educación intercultural". Septiembre del 2012 en MARTÍNEZ, 2014 pp.197).

“...No, no somos indios, los indios pasaron hace mucho tiempo, eran muy salvajes (...) si había en el Chaco una comunidad que todos tenían las rodillas para atrás, se ponían las rodillas para atrás, corrían los ñandúes y los cazaban..."

“...Decían que los indios mataban animales vivos (...) los cueteaban así cuando iban corriendo." (NAHUEL. Miembro de la comunidad. Registro de campo $\mathrm{N}^{\mathrm{o}}$ 34. Encuentro colectivo "Los significados de la educación intercultural". Septiembre del 2012 en Op.Cit, 2014, p.198).

“...Yo los escuchaba antes a mi mamá y mi papá porque ellos conocían a todos los que decían que eran paisanos y hablaban todos encriollados y hablaban como gringos y mi papá decía y estos...si todos son paisanos, son todos indios como yo, decía..." (SONIA. Referente de la comunidad. Registro de campo $\mathrm{N}^{\mathrm{o}}$ 34. Encuentro colectivo "Los significados de la educación intercultural". Septiembre del 2012 en Op. Cit, 2014, p.198).

La articulación entre el pueblo Mocoví y el Estado estuvo orientada por las políticas nacionales y provinciales indígenas, notando un proceso de invisibilización/visibilización.

En la década del '30 del siglo pasado, luego de Napalpí, a nivel nacional se desplegaron medidas políticas que se vinculaban a cuestionar las condiciones de explotación de los pueblos indígenas, a la vez, de instalar como debate en el congreso si los indígenas tenían que ser incorporados a las regulaciones jurídicas como ciudadanos con plenos derechos.

Durante el período entre 1946 y 1955, las movilizaciones indígenas se fueron incrementando y desplegando otros modos de reclamos como, por ejemplo, el denominado "malón de la paz" organizados por Kollas de la zona de Salta y Jujuy, quienes, demandando los títulos de tierras, deciden marchar a pie hasta Buenos Aires. 
Esta coyuntura histórica, tuvo características contradictorias, respecto a la relación entre el gobierno nacional, representado por Juan Domingo Perón y los pueblos indígenas; de la mano de un conjunto de reconocimientos para las comunidades, en términos de derechos sociales (regulaciones laborales) y políticos (documentos nacionales de identidad), determinadas luchas como las manifestadas por el malón de la paz fueron ignoradas por dicho gobierno (GORDILLO y HIRSCH, 2010).

La década de los sesenta enmarca, como hito de ruptura en las políticas indígenas, la realización del primer censo nacional y procesos de migraciones rurales-urbanos en todo el país, como consecuencia de crisis en las economías rurales.

Atravesado por este contexto a nivel nacional, las primeras familias Mocovíes llegan a Recreo en 1968, provenientes del norte de la provincia de Santa Fe (Colina Dolores, San Javier, Romang y San Roque), estableciéndose en las zonas de quintas para trabajar en condiciones de precariedad.

La llegada de estas familias no implicó, de acuerdo a uno de sus miembros, una vida como comunidad indígena, ya que la fuerte discriminación e invisibilización social tanto por parte del Estado como de la sociedad civil condujo a que negaran su "identidad cultural", durante años.

Recién en 1978, el proceso de evangelización de las iglesias evangélicas, se constituyó, según miembros de la comunidad, en una de las posibilidades para la formación de la misma, en tanto permitió que compartieran distintas actividades y colaboró en la “concientización” del valor de la cultura, la lengua, el origen y el aspecto espiritual: “...En 1978 se comenzó a evangelizar a los aborígenes, eso ayudó a juntarnos fue un punto muy importante para concientizar el valor de la cultura ante dios. Eso nos ayudó a estar hermanados todos en una creencia, posibilitó el diálogo con los ancianos, con todos" (ANTONIO. Referente de la comunidad. Registro de campo No31. Entrevista agosto de 2011 en MARTÍNEZ, 2014 pp.175).

En 1982, comienza a formarse el barrio Mocoví y en el año 1988 se organiza formalmente, y se identifica ante la sociedad como comunidad aborigen y comienzan los reclamos de forma organizadas, centrándose en trabajo, salud y la educación.

La forma de organización socio-política es similar a aquella previa a la conquista con un líder por cada clan o grupo tribal y un "Caycek" general para toda la comunidad, la 
diferencia central está dada en los mecanismos de elección del último, en la actualidad este es elegido.

“... Hoy en día todavía se manifiesta, todavía no está quebrado (refiere a la forma organizativa de la comunidad, abordada al principio del capítulo) (...) lo único que hay ahora no es una imposición, a lo mejor antiguamente, así imponía la figura de la persona cacique por su gran sabiduría, su gran personalidad, su gran poder de convencimiento, de dirigir; viendo continuamente la situación de todas las familias, era el más sabio, por eso se lo designaba cacique general de una comunidad(...) ahora también como que se adopta las cualidades de una persona que tiene mucha personalidad, dentro de la comunidad en este caso que ya está integrada entre criollos y todos, ahora tenemos un doble trabajo tenemos que elegir a la persona que tiene que tener una personalidad dentro de lo comunitario y dentro de los social; se elige esos tipos de personas..."(ANTONIO. Referente de la comunidad. Registro de campo No31. Entrevista Agosto.2011 en Op. Cit, 2014).

Las condiciones precarias de vida, atravesada por un contexto provincial y nacional de profundos quiebres estructurales, propició que en el año 1990 muchas personas Mocovíes se vieran afectadas por la tuberculosis, motivo por el cual, se solicita al gobierno la urgente atención a la salud. A partir de ese momento, se inicia un continuo trabajo junto con médicos y referentes de la comunidad para revertir la afección a esta enfermedad, a través de controles, campañas de vacunación, etc.

La organización indígena a nivel provincial, cobraba mayor visibilidad a partir de la concreción de OCASTAFE (Organización de Comunidades Aborígenes de Santa Fe) en 1989, aproximadamente.

Paralelo a la lucha por la salud, estaba el proyecto comunitario de formar una experiencia de educación intercultural con enseñanza de su propia lengua, ya que consideraban que lo educativo, también, tiene que ver con la saludi.

En el año 1990, comienzan a funcionar unos centros de alfabetización de adultos, esto permitió el contacto con docentes, un aspecto importante para la formación de la escuela.

Ese mismo año se presenta un anteproyecto de ley para la creación de la escuela diseñado por docentes y miembros de la comunidad, que se aprueba en 1991y comienza a funcionar en 1992. 
Para la década de los noventa, el 90\% de las familias Mocovíes radicada en la zona de Recreo, se desempeñaba como peones de quintas con una mínima remuneración que no era suficiente para cubrir las necesidades básicas, en menor porcentaje se encontraban quienes vendían artesanía y aquellas familias que realizaban diversos trabajos en condiciones de precariedad (“Changas”).

Los objetivos de la creación de la escuela y la realidad sociocultural que atravesaba a la comunidad, quedaron inscriptos en la memoria de los miembros de la comunidad, de los docentes que participaron en ella, que cobra vida en el relato de esta experiencia y en el proyecto de la escuela.

De acuerdo a este último, los objetivos de la creación de la escuela eran:

“...El rol fundamental de la escuela será el educacional, el rescate cultural y la inserción con todas las otras comunidades.

Contemplará, también, el aspecto asistencial con el funcionamiento del comedor escolar.

Es prioridad el rescate del niño que no concurre a la escuela. -que los niños de sobre edad concurran con grupos que tengan sus propios intereses, formando los grados de recuperación que le permitan avanzar dentro de la escolaridad primaria sin la repetición. Para ello se trabajará con movilidad de los grupos dentro de los ciclos o niveles.

-que los niños de la comunidad tomen confianza de sí mismo a partir de conocer, comprender su historia, su cultural, dominar su lengua, su situación actual, lo que les permitirá en un futuro próximo la integración a otras comunidades en pie de igualdad de oportunidades.

-que el proyecto sea constantemente evaluado para su permanente actualización" (PROYECTO ESCUELA BILINGÜE. Comunidad Mocoví de Recreo. Escuela Primaria Común Diurna S/R en MARTíNEZ, 2014, pp.200).

El lugar de la escuela se iba constituyendo en la trama del barrio y la comunidad, acompañando las problemáticas laborales, de salud y comunitarias de los Mocovíes, tal como figura en el apartado PROYECCION DE LA ESCUELA dentro del Proyecto de la escuelai

La escolarización de los miembros de la comunidad era una de las preocupaciones, ya que el 30\%(aproximadamente) no había terminado la primaria y entre el 15 y $20 \%$ no había asistido nunca.

Diferentes motivos provocaron estos porcentajes entre ellos se encuentran: la distancia de las escuelas a las que tenían que concurrir (entre 4 y $5 \mathrm{Km}$ ida y vuelta) y el cruce de la ruta que produjo accidentes y hasta la muerte de una niña de la comunidad; la discriminación que sufrieron diferentes Mocovíes y, en algunos casos la diferencia lingüística: 
“... La escuela surgió por un accidente de una nena; cuando la gente se dio cuenta de que necesitaban dentro de la comunidad, también, porque cuando íbamos a la otra escuela, siempre volvíamos llorando, nos pegaban se reían, cuando recién se identificaron acá fue muy difícil; en la escuela tanto los docentes como los alumnos nos trataban mal, nos pegaban, nos decían indios, indios mugrosos(...) los docentes era como que en la escuela no nos trataban mal pero era como que no nos defendían (...) nosotros nos enojábamos con mi mamá porque no entendíamos porque estaban los indios; siempre nos golpeaban, en la escuela nunca tuve amigas y era como que todos los que íbamos de acá (se refiere a la comunidad) estábamos siempre juntitos, no nos juntábamos con nadie porque nadie se quería juntar con nosotros y bueno....por eso surge la escuela; después que hubo el accidente de una nena que falleció porque tuvo un accidente al cruzar(cruzaban la ruta para ir a la escuela); los padres nos cambiaron acá.(....) O sea la palabra que más nos dolió era indio, indio mugriento que siempre nos decían....". (LAURA. Miembro de la comunidad Mocoví que trabaja como maestra idónea. Registro de campo N ${ }^{a}$ 28. Entrevista Mayo 2010 en Op. Cit, 2014, pp.201)

“...Al haber una comunidad con raíces culturales muy fuertes, mantienen toda una idiosincrasia diferente al resto de la sociedad, tienen valores muy importantes que conservan, aunque asimilan la otra cultura, no logran como aprender.

Como que esconden su realidad cultural en la que viven en el seno familiar (...) nosotros creemos que los chicos mantienen una estructura de la lengua, de la forma de pensar, que a veces no concuerda con el sistema educativo..." (ANTONIO, miembro de la comunidad. Registro de campo №31. Entrevista Agosto del 2011 en Op. Cit, 2014, pp. 202).

La fundación de esta escuela, forma parte de procesos más generales del contexto histórico-social a nivel provincial y nacional y del impulso de experiencias educativas indígenas durante la década de los noventa en la América Latina (ACHILLI, 2010, p.292).

El período comprendido entre el 2003-2015 muestra un conjunto de políticas públicas orientadas a diferentes grupos indígenas como fueron: el reconocimiento de la EIB como modalidad educativa, la creación del CEAPI, la configuración del registro censal de las poblaciones originarias para la entrega de Tierras, la propuesta de un programa de inclusión de Pueblos Originarios en el Nivel Superior.

Sin embargo, estas acciones a nivel Nacional, las cuales fueron replicadas con resignificaciones en la Provincia de Santa Fe, no fueron suficientes para transformar completamente la vida cotidiana de las familias Mocovíes, las cuales viven en mayor medida 
del trabajo informal, de la venta de artesanía y la participación en la administración pública, en algunos casos.

\section{La escuela Mocoviiii}

En la provincia de Santa Fe, entre 1990 y 1992 se formaron tres escuelas de “educación intercultural bilingüe” (EIB) dos Tobas en Rosario y una Mocoví en Recreo.

Estas primeras experiencias "formales" de EIB estuvieron atravesadas por diferentes procesos que involucran el cruce de distintas dimensiones contextuales; por un lado, la inserción de estas escuelas en tramas barriales fragmentadas que se relaciona con el contexto socio-histórico mayor neoliberal. Por otro lado, la lucha de diferentes Pueblos Indígenas en América Latina que tuvieron a la educación y a la escuela entre sus disputas, a los procesos que se inauguran con el ingreso de los reclamos indígenas en las regulaciones jurídicas a nivel internacional, nacional y provincial, mucho de los cuales tuvieron la activa participación de los propios Pueblos.

Para la comunidad Mocoví, tanto en la etapa previa a la formación de la escuela, como en sus comienzos, se visibilizaba que uno de los problemas centrales era la falta de comunicación entre docentes y alumnos. Esto era producido por el entrecruzamiento de varias cuestiones, una se asociaba a la realidad diferente con la que se encontraba el docente, vinculado con esto, la pertenencia de los chicos a una comunidad indígena y a los procesos de discriminación por parte de niños y adultos hacia ellos.

Frente a esta realidad escolar y cultural diferente, una de las principales estrategias en las que se centraron fue en la valoración de la "propia cultura" como punto de partida de la construcción de la enseñanza y aprendizaje.

Esta valoración de su "cultura", a través de la transmisión de valores, la lengua, las creencias y las costumbres en la escuela, de acuerdo a los sujetos involucrados, se constituye en "conocimientos válidos" que fortalecen la autoestima de los alumnos y eso permite tanto el aprendizaje de otros conocimientos como la constitución de una "identidad cultural".

“...Cuando los chicos ven a la escuela como algo suyo es como que lo incentiva a cuidar la escuela a darle el valor que corresponde; las familias, también, a aportar, a ayudar a que ese chico pueda aprender en todo lo que 
tiene que ver con la capacitación que brinda la escuela y fue mejorando, pero muy lento (...).

(...) Se ha avanzado muy bien, algunos están en la secundaria, algunos están estudiando para ser profesionales, se ha avanzado bastante. Lo que rescatamos de esos chicos es que salen de la escuela con identidad cultural (...)

(...) Ahora los chicos tienen gran aceptación de su identidad cultural y eso sirve para proyectar su vida, para fortalecerse, enriquecerse y proyectarse y encarar más profundamente los derechos como seres humanos y en eso les sirve mucho la escuela...". (ANTONIO, miembro de la comunidad. Registro de campo ํo31. Entrevista Agosto del 2011 en MARTÍNEZ, 2014, pp.204).

La formación de estas escuelas en la provincia tuvo una importante presencia de las comunidades, tanto a través de sus representantes, como de los maestros idóneos y de otros profesionales quienes participaron en las organizaciones institucionales, diseño curricular y en el acompañamiento de los alumnos junto con los directivos.

“...Estaba muy latente el tema de la discriminación, sentirse discriminado, marginado por una sociedad, por todos los sistemas de gobiernos. Eso hacía que tanto el chico como la familia no lograba integrarlo al sistema educativo. Cuando fuimos viendo todo eso en las reuniones con directivos y docentes se iba viendo continuamente todas las situaciones que había que ir contrarrestando y ver de qué forma podía haber una educación que se adecuara a los aborígenes, fue un trabajo muy costoso para los docentes, para los directivos, también, porque no había una experiencia así acá, no teníamos elementos, nada escrito sobre el tema, lo teníamos que hacer a fuerza de experiencia...”. (ANTONIO, miembro de la comunidad. Registro de campo No31. Entrevista Agosto del 2011 Op. Cit, 2014).

En la trama de las constituciones de estas instituciones educativas, se pueden notar, huellas de las políticas educativas de los noventa y los atravesamientos históricos, desde donde se despliegan concepciones de "educación intercultural/educación indígena" y marcas de la organización del sistema educativo.

La formación de la escuela Mocoví, fue el resultado de la condensación de distintas aristas que refieren a contextos tanto próximos como más amplios, en primer término, implicó un hito histórico relacionado al reconocimiento de las primeras escuelas de educación intercultural bilingüe/educación indígena de la provincia, junto con las dos Tobas de Rosario.

Formó y forma parte, también, de una lucha más amplia respecto a proyectos etnopolíticos de la comunidad Mocoví de Recreo, en el marco de movimientos indígenas en 
América Latina; a su vez, expresa las huellas de una coyuntura histórico-social de profunda crisis que se visibilizó en la cotidianeidad escolar y de los modos de intervención y delimitación de colectivos de los planes y programas focalizados.

La escuela se ubica, geográficamente, en una zona de quintas, próxima a la ruta $\mathrm{N}^{\mathrm{o}} 11$ en las inmediaciones del casco urbano de Recreo, frente al salón comunitario en el barrio Mocoví.

Como lo destaca en la legislación que la regula, es una institución de educación inicial, pre-primaria y primaria modalidad intercultural bilingüe con comedor. En el año 2017 la Provincia de Santa Fe, reconoce a la escuela secundaria dentro de la modalidad de Educación Intercultural Bilingüe.

Durante nuestro primer año de trabajo de campo (2009-2010) la escuela estaba en construcción para la incorporación de más aulas y salas, eso hacía que se trabajara en jornadas reducidas en tres turnos diferentes (de tres horas cada bloque, aproximadamente) y con los obreros en el cotidiano escolar.

El comedor, pertenece a la escuela, pero a él asisten alumnos de otras escuelas, se encuentra enfrente de la institución al lado del centro comunitario de la comunidad y en él trabajan miembros de la comunidad que, también, envían a sus hijos a la escuela.

“...El comedor queda bien enfrente a la escuela a unos metros, los chicos van con las maestras en fila, al llegar había cuatro mesas largas (entraban veinte personas por mesa), en las mesas había pan (no logré ver qué estaban tomando), la comida era arroz con milanesas.

Había una señora al fondo vestida con una chaqueta y cofia celeste y otro señor al lado.

Sobre la pared al fondo (viéndolo de frente) en letras negras imprentas había un escrito:

Este barrio es bueno como hombre Mocoví, bello como mujer Mocoví..." (REGISTRO DE CAMPO. N ${ }^{\circ}$ 26. Observación participante. Mayo del 2009 en Martínez, 2014, pp. 213).

En términos de organización, la escuela cuenta tanto con docentes de grados y directivos "comunes", es decir, formados para trabajar en cualquier institución escolar, con maestros idóneos que son miembros y referentes de la comunidad Mocoví que enseñan idioma y cultura y la articulación de los conocimientos legitimados culturalmente por la comunidad con los conocimientos curriculares estipulados ministerialmente. 
La comunidad participa a través del Consejo de Idioma y Cultura quien se encarga de seleccionar y acompañar los contenidos culturales y los modos que se transmiten en la escuela.

De acuerdo a los miembros de la comunidad y a los especialistas en la temática las horas destinadas a la enseñanza de la lengua y los contenidos específicos de la Cultura son escasos, entre una y dos horas semanales por grado. Como forma de compensar esto, surgen propuestas como la configuración de un diseño curricular que integre contenidos específicos de la cosmovisión y lengua Moqoit y aquellos comunes a todas las escuelas y el trabajo en el Centro comunitario en conjunto con el Consejo de Idioma y Cultura ${ }^{\text {iv }}$, centrado en la enseñanza de la lengua.

La elaboración del diseño curricular integrado estuvo a cargo de uno de los Maestros idóneos y referentes de la comunidad y uno de los directivos. Tuvimos acceso a una sección de este material, de cual, retomamos aquellos aspectos significativos en la trama de la configuración de la etnicidad. Por ejemplo, algunos de los temas son:

“...Valores: El valor de la vida desde la cosmovisión de distintos pueblos. La importancia de la religiosidad. La cosmovisión aborigen respecto al origen de la vida. La razón de las creencias. La transmisión de las leyendas y su mensaje educativo, abajo después de varios espacios en blanco; Persona: Los ideales de persona para la Cultura Mocoví. Los ideales culturales indígenas y la interrelación con la sociedad. Coincidencias y diferencias en cuanto a los ideales.

"El tiempo social": Análisis de los orígenes de las familias del barrio Mocoví y de otras localidades; Las sociedades indígenas en el pasado y en el presente en la provincia de Santa Fe; Colonización europea. Consecuencias. Proceso de aculturación. Asentamientos aborígenes definitivos. Situación actual de las lenguas indígenas, espacios en blanco; las fechas significativas para las comunidades indígenas.

Del tema organizador "Las sociedades y los espacios geográficos"; para quinto grado, se propone: La población aborigen actual en la República Argentina. Localización. Las distintas etnias. Población; con cuatro espacios en blanco aparece la temática de las normas: El derecho a las tierras como pueblos originarios a nivel nacional. Documentos. Concesión de tierras. Reclamos actuales.

"El hombre y la salud" es el centro de interés desde el cual se despliegan distintas problemáticas. Para Séptimo grado: El cuidado de la salud desde la cosmovisión aborigen; La pubertad y la adolescencia desde el concepto cultural aborigen. El rol de los abuelos en la educación sexual de los adolescentes en el pasado. Comparación con la actualidad; El significado de 
un nacimiento para la comunidad Mocoví. Los cuidados comunitarios de la madre y el bebé (....) Para Séptimo grado: Los astros; La luna y las estrellas, su relación con distintos aspectos sociales de la comunidad aborigen (Lo sentimental; la fraternidad y las relaciones humanas); comparación con la ciencia: la astrología; las estrellas, el lucero como referencia de orientación; la cruz del sur, leyenda Mocoví: El camino del ñandú; Otras constelaciones como referencia de orientación. El pozo del toro: El carancho. Los perros. El ñandú. Otros. Leyendas que explican su formación. Mensajes que transmiten..." (ANTONIO Y VALERIA Secuenciación de los contenidos conceptuales. Segundo y tercer ciclo, 2009. S/R en MARTÍNEZ, 2014, pp.227)

Los materiales de enseñanza que, de forma aproximada, intentamos describir más arriba y que es el resultado del aporte del entrecruzamiento de saberes de quienes forman parte de las enseñanzas-aprendizajes en la vida cotidiana escolar. Representan, también, apropiaciones por parte de la comunidad Mocoví de conocimientos y estrategias de enseñanza escolar y, a su vez, constituyen aportes cruciales para los conocimientos complejizándolos.

En este sentido, retomamos lo analizado por la autora antes citada, que si bien alude a una reunión específica donde se estaba acordando los criterios y contenidos seleccionados para formación de la currícula de educación indígena común, nos dan la posibilidad de entender la currícula de esta escuela.

“... Durante los encuentros surgieron diferentes visiones del trabajo en torno a los conocimientos con distintas posturas, una de ellas, se presentaba como más relacional en tanto ciertos modos de enfocar algunos contenidos podían articularse o integrarse en distintas áreas(....) De hecho, en estos procesos, esa visión más relacional de los conocimientos en tanto se resisten a ser divididos en compartimentos, fue asumida, fundamentalmente, aunque no de modo exclusivo, por maestros o representantes indígenas..." (ACHILLI, 2010, p.316).

En la propuesta que abordamos, la integración o articulación, tiene como punto de partida la organización a través de diferentes ejes de trabajo con determinada amplitud que dan la posibilidad de la incorporación de diferentes temáticas afines y estás, a su vez, forman parte de lo que la comunidad define como significativo para la transmisión a sus generaciones y los modos de hacerlo, donde la escuela, es un espacio importante de labor con los mismos pero, también, lo es la familia y la comunidad. 
"La selección de los contenidos de la propuesta curricular, y su presentación dan una imagen de una cultura como un todo coherente y definido en el tiempo, sin embargo, esto que aparece como una construcción reificada de la cultura, cuando implica a Pueblos Indígenas pueden ser signos de construcciones políticas que van adquiriendo distintos significados (ACHILLI, 2010, p.317).

\section{La educación indígena dentro del proyecto comunitario.}

Dentro del corpus de entrevistas, se trabajó con determinados maestros idóneos que, a su vez, integraban en ese momento órganos de definiciones de políticas educativas a nivel nacional como es el CEAPI (Consejo Educativo Autónomo de Pueblos Indígenas) y fueron responsables del diseño de las propuestas educativas abordadas con anterioridad.

También, trabajamos con jóvenes que se están formando como maestros idóneos, egresados de las primeras generaciones de la escuela y que forman parte de la lucha de la comunidad y con alumnos de la secundaria que fueron egresados de la escuela primaria y participan activamente.

Las entrevistas y encuentro tenían como núcleo de abordaje la "Educación Intercultural Bilingüe" y la vida cotidiana de la comunidad en la escuela. Como lo destacaremos a continuación, la "educación intercultural” para los Mocovíes de Recreo es uno de los ejes centrales de la lucha y se inscribe en un proyecto comunitario mayor.

“.. ya tenemos una organización dentro de...en general así, una conciencia nueva, principalmente, de valoración de los aborígenes, uno no puede luchar por ninguna cosa si no está convencido de quien es, es un trabajo muy arduo que lo estamos haciendo desde la escuela ese trabajo, por eso cuando hemos proyectado la comunidad uno de los objetivos principales era la escuela, la educación porque decíamos que desde el aula podíamos transmitir esos valores que después en el futuro van a tener que analizarlos mucho y verlos, los chicos porque para que entiendan que ellos sino dan ese valor a su cultura difícilmente puedan luchar por los derechos que le corresponden eso se las ha hecho a los jóvenes, a los ancianos, a todos, nosotros yo hemos trabajado de esa forma mucho para crear esa conciencia y no solo de la riqueza cultural que tienen sino que tienen que interiorizarse de la otra cultura, sus leyes, sus formas de vida, su organización para que uno pueda, no sé si adaptarse o acomodarse, adecuarse a un sistema organizativo que ya 
es muy influyente, dentro de todo eso uno tiene que hacer el trabajo de estudiar porque si no estudiamos nada quedo ahí en que tenemos un derecho pero no lo podemos abordar ni reclamar porque no lo conozco, no sé cómo se maneja; en eso, es que los chicos hoy en día puedan tener una nueva conciencia, no para hacer una guerra, no para pelear, en una forma inteligente puedan proyectarse en la vida, de forma comunitaria o con lo familiar; nosotros tenemos una forma tratamos de mantener la forma comunitaria; tratamos de adecuarnos a un sistema con esa forma comunitaria que cuando uno viene desde afuera no lo ve pero dentro del seno familiar está latente esa concepción de vida, esa sería la forma y tratar de capacitar a más personas que estudien nuestras leyes y un día sean profesionales y sean defensores de las leyes para poder defender, proyectar porque las comunidades aborígenes hasta ahora están en estado marginal no hay una muy buena atención por parte del Estado en todo lo que respecta en lo educativo, en la salud, en la cuestión tierras no están siendo atendido como debería ser que no tendría que ser un problema sino que los mismos aborígenes tienen capacidad para proyectarse solos, nada más que a veces no tienen la oportunidad de poder hacer eso, hasta el momento. Creo, también, que pasa mucho por tener una conciencia y una capacidad para enfrentar una vida que tiene que ser tratada de otra forma no creo que se pierda lo de antes, lo comunitario, pero ya estamos en un mundo muy envolvente que conservar lo nuestro habrá que trabajar a conciencia con todos los chicos, los abuelos (...) para no perder la forma organizativa nuestra y que la tenemos, en realidad la tenemos.

Entrevistadora ¿Cómo se manifiesta esa forma organizativa?

Antonio: En el aspecto económico, yo le digo, (...) cada uno tiene que arreglarse como pueda, depende si tienen trabajo en relación de dependencia, en una forma autónoma o tienen los planes sociales que hay ahora del Estado. Económicamente, no hay un soporte ni una clase de soporte, nada (...) En la comunidad en la actualidad hay más de trescientas familias., la mayoría trabaja a partir de "changas" y muchos planes sociales de la municipalidad, muy bajo el porcentaje de empleados, títulos de las tierras. No se tiene el título de la figura de propiedad comunitaria. Somos un pueblo comunitario...". (ANTONIO, miembro de la comunidad. Registro de campo №31. Entrevista Agosto del 2011 en MARTíNEZ, 2014, pp.175).

Seleccionamos estos fragmentos de entrevista para comenzar a desentrañar los aspectos centrales de los significados en relación a la educación indígena, en especial, nos interesa destacar cómo la misma se inscribe en una lucha mayor que involucra dos aspectos claves para la reproducción de la vida cotidiana de la comunidad, uno se vincula a la conciencia nueva de valorización de los aborígenes y otro, íntimamente relacionado con este, con el aprendizaje a modo de apropiación de los derechos como herramienta de lucha para una proyección comunitaria que les posibilite una relación, desde otro lugar, con el Estado, conservando su forma organizativa que se expresa en la frase Somos un Pueblo Comunitario. 
La escuela se integra a un proyecto mayor que implica el reclamo y la conquista de sus derechos como Pueblo Indígena, esto incluye la salud, las tierras y la educación intercultural.

Los significados respecto a los modos de transmisión de los aspectos culturales, los valores, las creencias tienen un anclaje histórico para el Pueblo Mocoví que está sustentado en sus cosmovisiones y en las tramas socioculturales propias del pueblo, algunas de las cuales se fueron transformando por la dinámica histórica dentro de los marcos de relaciones interétnicas de desigualdad.

“...La cuestión de la salud, antiguamente, la organización que tenían los aborígenes, tenían sus propios curanderos, hechiceros y sus brujos cuando hace contacto con la otra cultura a esas tres figuras la hicieron una o hechicero o curandero o brujo y cada uno formaba parte de lo que tenían que ver en la salud ya sea física, mental, espiritual eran un componente muy importante, eran personas muy útiles dentro de una comunidad; si había enfermedades físicas la atendía el curandero era el que tenía toda la sabiduría en el tratamiento con las hierbas medicinales y el tratamiento de qué enfermedades tenía; el hechicero vendría ser lo que ahora llamamos psicológico, el que atendía cuando uno tenía problemas de ansiedad, mentales, todo lo que tenía que ver con lo psicológico; era visto como que hacía mal y no, nosotros no creíamos que hiciera mal era el que hacía todo el trabajo de restauración de pareja cuando se separaban cuando eran novios o esposos y se separaban era importante para la gente que padecía eso y el brujo era el que tenía la visión, de todo lo que tenía que pasar en las comunidades, el que veía más allá; veía lo que no podían ver el cacique; los líderes o los jefes de familia (...) era el consultor de eso, vamos a decir, porque se lo consultaba continuamente el destino de una comunidad o de una familia; el que después lo han relacionado muy mal como que era el que mataba y era totalmente diferente.

Yo lo que le estoy diciendo no es una cuestión que me lo contaron, yo lo he vivido uno no se daba cuenta de lo importancia que tenía en ese momento pero ahora que ha pasado el tiempo uno ve cuán importante eran esas tres figuras en la comunidad, cuán importante eran en lo organizativo; porque era el que veía (se refiere al brujo) el futuro del pueblo o de una comunidad en lo organizativo lo consultaban los líderes y el cacique, continuamente, trabajaban en conjunto.

Siempre cuando uno lee unos libros que hablan de sobre estas cuestiones a veces hay partes, algunos conceptos erróneos que han hecho(...) nosotros dentro de la comunidad teníamos los que llamábamos maestros que eran los que enseñaban a los chicos y eran los abuelos, los abuelos eran los que transmitían todos esos valores que tenía un pueblo para que esos que iban creciendo tuvieron en cuenta cómo eran las reglas de vida en un pueblo que tenía una vida totalmente comunitaria(...) cada uno tenía su especialidad, estaba el que enseñaba la conducta de la vida, estaba el que transmitía cómo pescar, cómo cazar, cómo estar en el monte el que transmitía las leyendas, el las creencias, el que transmitía las leyes naturales que había en la tierra, tenía 
cada uno una particularidad de enseñar cada aspecto y eso hoy en día se perdió un poco todo eso porque nos ha quitado lugar, la televisión, la música todo el bombardeo de la otra cultura(....) no era cualquiera que era brujo, no era cualquiera que era hechicero, no era cualquiera que era curandero, era como que ya estaban destinados a ser eso; hasta hoy en día algunos jóvenes ya hacen la práctica de la curandería, algunas cosas de hechicería(...) lo que se ha perdido un poco es la figura del brujo; no lo vemos mucho acá; que hace 15 o 20 años atrás veíamos(...) era una persona muy importante aunque cuando hace contacto con la otra cultura, esta última le enseña que el brujo era malo, diabólico y nada que ver(...) más cuando fueron evangelizados todos los pueblos, con más razón se aferran a las religiones y dejan de lado toda la importancia y toda la sabiduría que tenía su propio pueblo..."(ANTONIO, miembro de la comunidad. Registro de campo $\mathrm{N}^{\circ} 31$. Entrevista Agosto del 2011 en MARTÍNEZ, 2014, pp.176).

La historia del Pueblo Mocoví está atravesada por experiencias dolorosas que llevaron a esta comunidad a esconder y negar su identidad, ese silenciamiento de la pertenencia sociocultural se revive en los relatos de las vivencias y condujeron a la pérdida progresiva del idioma de tradición oral (GUALDIERI, 2004).

Esto quedó expresado en el encuentro colectivo con los miembros de la comunidad. Como disparador del encuentro, los jóvenes decidieron comentar su experiencia en un proyecto de investigación que realizaron con la escuela secundaria. El objetivo de este trabajo era el acercamiento de los jóvenes a los ancianos de la comunidad desde el lugar de la transmisión de saberes y conocimientos de su historia, el idioma, las formas de organización sociopolíticas y sus experiencias de vida. Paralelamente, cuando los jóvenes iban relatando esta labor y lo que significó para ellos, los otros miembros de la comunidad, participaban aportando sus conocimientos y sus propias vivencias, estas están atravesadas por la lucha de la comunidad y por el sufrimiento, producto de profundos procesos de discriminación, que orientaron a que como forma de sobrevivir, negaran su identidad y su idioma por años.

“...Los ancianos quedan poco, son cuatro o cinco, a veces no pueden hablar, se ponen mal..." (Ignacio. Miembro de la comunidad. Encuentro colectivo "los significados de la educación intercultural" junto a jóvenes y miembros del consejo de idioma y cultura. Registro de campo No34. Septiembre, 2012)

“...Difícil hablar con los mocovíes, hay que saber tratar con las personas(...) hay que tomar confianza y recién ahí empezar a hablar, se empiezan con las anécdotas de lo que era antes y se empieza a decir todo lo que vivieron; vergüenza, hambre, cosas así y más que nada se vio en toda la investigación la lengua, cómo se fue perdiendo la lengua y el no querer aceptar ser aborigen era una cosa que en todas las ocasiones que tuvimos de charlar con gente mayor Mocoví se dio eso de la lengua..."(LUIS. Miembro de la comunidad. Encuentro colectivo "los significados de la educación intercultural" junto a jóvenes y miembros del consejo de idioma y cultura. 
Registro de campo №34. Septiembre, 2012 en MARTíNEZ, 2014 pp 235 Políticas educativas y Diversidad sociocultural. Un estudio socioantropológico sobre la construcción de políticas y prácticas educativas acerca de la atención a la diversidad, tesis doctoral en Humanidades y Artes mención Antropología, UNR, Santa Fe, Mimeo).

Consideramos que la dinámica del idioma puede comprenderse en la trama mayor no sólo de las formas de relación entre el Pueblo Mocoví con el Estado, sino, también, podría pensarse como una de las aristas de la lucha de la comunidad.

Esto último, lo notamos por las distintas formas que está desplegando la comunidad respecto a la construcción de procesos de enseñanza-aprendizaje que involucren el "idioma y la cultura", ya sea desde la incorporación de la escritura; como desde la labor desde el centro comunitario de talleres de "idioma y cultura"; las propuestas de las familias de acompañar con la comunicación de la misma desde la casa, e incluso desde las legislaciones que contemplan el rescate de la lengua y la cultura, entre otra serie de derechos.

En este sentido, retomamos los aportes de Hecht (2010) en su investigación de tesis doctoral referida a los procesos de socialización lingüística de niños en un barrio Toba.

La autora plantea dos momentos claves para la dinámica linguística una se vincula al momento de asentamiento de la comunidad en el barrio, la inserción y la constitución de la trama barrial donde el idioma era asociada a una lengua desprestigiada; la otra etapa está asociada al momento posterior de constitución del espacio donde la lengua en los procesos de construcciones identitarias, se erigió en un símbolo identitario de poder y de prestigio, dentro del barrio.

Para los sujetos entrevistados la pérdida de la lengua y la transmisión de los modos de vida pasados de generación a generación está asociada al sistema que quiere borrar al ser aborigen.

“.... El sistema quiere borrar ahí el ser aborigen, nuestro vivir, nuestra forma de ser.

Con la ley, los políticos es como que nos quieren borrar las lenguas (...) quieren que nos insertemos a las formas que ellos viven (...)

Los chicos de hoy miran mucha televisión, muchos dibujitos..." (IGNACIO. Miembro de la comunidad. Encuentro colectivo "los significados de la educación intercultural". Registro de campo N³4. Septiembre, 2012 en MARTÍNEZ, 2014, pp.237).

“.... El sistema no le da la importancia y el valor que deberían tener las culturas para transmitirla dentro del aula (...). 
(...) En realidad es el sistema el que te quiere borrar y te quiere sacar porque nosotros con todo lo que estamos haciendo con este trabajo, tenemos el gran problema(...) uno es como que disfraza la educación intercultural bilingüe donde decimos bueno esta escuela es intercultural y bilingüe pero en realidad el trabajo que lleva adentro de la escuela es un espacio tan pequeñito que no alcanza a llenar ese vacío que en realidad tendría que meterle (...) entonces es el sistema y yo lo interpreto muy bien...es el sistema....." (ANTONIO. Referente de la comunidad. Encuentro colectivo "los significados de la educación intercultural”. Registro de campo N³4. Septiembre, 2012 en Op.Cit, 2014, pp. 238).

Acá podemos ir notando como se va delimitando un nosotros sustentado en la idea de ser aborigen confrontado a un sistema que intenta borrarlo. Estas percepciones, van mostrando la dinámica identitaria en los atravesamientos urbanos que suponen tener presentes los modos de inserción y constitución del barrio, las formas y los motivos a partir de los cuales se fue configurando la comunidad.

“...Porque tenés el sistema que te machaca y tenés alrededor la sociedad con una forma de vida distinta a la forma de vida que estamos planteando como comunidades aborígenes de mantener formas de vida, vivencias, organizaciones, espiritualidad(...) diferente a un sistema que hay que aprender, aprender, para luego utilizarlo no se valora la persona, las poblaciones indígenas valoran mucho el ser mucho más de lo que plantea el otro sistema que dice que la capacitación del saber muchísimo hace que después tengas un camino mucho más próspero, es distinto(...) por esa razón los aborígenes no tenían proyectos a futuro vivían al día......(A NTONIO.

Referente de la comunidad. Encuentro colectivo "los significados de la

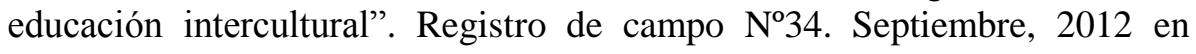
Op.Cit, 2014).

“.... pero el trabajo que hay que hacer para generar una conciencia de cómo meterle al chico, los valores que tiene la cultura creo que va a ser un proceso bastante largo, nosotros llevamos recién 20 años y hemos logrado una conciencia mínimamente de valoración de la persona con identidad pero falta muchísimo, calculamos que no sé si llegamos al 10\% del rescate de lograr meter todos los valores de la cultura dentro de la cabeza..." (ANTONIO. Referente de la comunidad. Encuentro colectivo "los significados de la educación intercultural". Registro de campo N³4. Septiembre, 2012 en MARTÍNEZ, 2014, pp.245).

Consideramos que la idea de una nueva conciencia de valoración de la persona con identidad, se relaciona con el planteo de Vázquez (2000) respecto a la dimensión ideológica denominada como etnicidad como sustento de una lucha etnopolítica que se concreta en el marco de procesos étnicos identitarios. 
En este sentido, la forma de organización comunitaria, el idioma y lo que expresan como cultura (transmisión de valores, creencias, vivencias y espiritualidad) se van articulando construyendo un nosotros como comunidad Mocoví.

Aquí el rol de la escuela y dentro de ella, el trabajo de la comunidad es crucial en la generación de esa nueva conciencia de revalorización de los aborígenes como lo expresan representantes de la comunidad.

A su vez, esto se relaciona con el aprendizaje desde la apropiación de las cuestiones centrales que enseña la escuela para que los chicos puedan proyectarse de forma comunitaria, conociendo cuáles son sus derechos.

\begin{abstract}
“......Nosotros lo que hemos logrado concientizar a los maestros y cómo trabajar que no solamente trabajando nosotros en el aula con los chicos sino que el maestro dentro de sus contenidos hace mención de la interculturalidad eso es muy importante para la concientización de los chicos, porque los chicos ven que el espectro cultural está siendo tratado dentro de las aulas de forma respetuosa de una vida intercultural de dos culturas respetado y eso es muy importante porque (...) eso es muy importante, se trabajan mucho las fechas significativas que hay, sobre la historia de los aborígenes, del ser aborigen y eso tiene un impacto social para los aborígenes y para los que no son aborígenes, también(...) como nosotros nos hemos puesto de pie para luchar y defender esta cultura que los mismos jóvenes; eso que trabajamos en el aula es muy importante, nos hemos metido mucho dentro de un sistema que no quería saber nada...."(ANTONIO. Referente de la comunidad. Encuentro colectivo "los significados de la educación intercultural". Registro de campo N³4. Septiembre, 2012 en MARTÍNEZ, 2014).
\end{abstract}

\title{
5. Las experiencias de educación indígena en miembros de la comunidad
}

A partir de este apartado nos interesa aproximarnos a lo que significa la "educación intercultural" para tres jóvenes miembros de la comunidad, que vivieron la experiencia de la escuela primaria.

“...Acá (se refiere a la escuela de EIB) nos sentíamos libres, podíamos expresarnos más, a lo mejor si yo contaba que mi abuelo antes escuchaba el negrito del agua, una historia Mocoví, que mi abuelo decía que nació, que escuchó el llanto, nosotros nos sentíamos libres de contarlo porque sabíamos que acá los chicos sabían la historia, en cambio, si lo contábamos allá(se 
refiere a la escuela a la que asistía antes), alguna historia o algo se nos burlaban; siempre estaba la burla, acá, fue más libre nos sentíamos en nuestro lugar..." (LAURA. Maestra idónea. Miembro de la comunidad. Encuentro colectivo "los significados de la educación intercultural". Registro de campo N³4. Septiembre, 2012 en MARTÍNEZ, 2014, pp.241).

“...Para mí, la educación intercultural es mi vida (...) (LUIS. Miembro de la comunidad. Encuentro colectivo "los significados de la educación intercultural”. Registro de campo No34. Septiembre, 2012 en Op.Cit, 2014, pp.242).

(...) Me pasó...yo estuve en la escuela desde jardín hasta quinto año, gracias a dios se terminó la discriminación por la lucha de la gente del barrio, de la comunidad, pusieron mucha garra, muchos esfuerzos, me crié en base a creencias lo tenía a Antonio de profesor maestro son cosas así, son cosas inolvidables a veces escucho así y empiezo a retroceder, las creencias que tengo y que me contaron siempre van a quedar las tengo en la cabeza, de tanto que lo tengo en la cabeza las llegué a escribir las tenía en la cabeza.

"...La educación intercultural es transmitir la cultura a quienes no la tengan (...) es inventariar la forma de hablar, la historia (...) intercambiar las cosas, lo que aprendí en la escuela es eso, intercambiar la cultura..." (IGNACIO. Miembro de la comunidad. Encuentro colectivo "los significados de la educación intercultural". Registro de campo N³4. Septiembre, 2012 en Op. Cit, 2014).

Estos fragmentos se relacionan con lo que estuvimos abordando con anterioridad en relación al lugar de la escuela en la configuración de etnicidad como una ideología que se vincula a la vida comunitaria, al vínculo con la naturaleza y a la recuperación de la lengua en el marco del proyecto comunitario mayor.

Resulta interesante destacar cómo la experiencia de esta escuela indígena, se constituyó para estos tres miembros de la comunidad en un espacio que se vinculaba a $s u$ vida, a la lucha de la comunidad, a la transmisión de su cultura.

Estos procesos, a su vez, de acuerdo a las apreciaciones de los maestros idóneos, docentes y vice-directivos de la escuela, fueron claves para la enseñanza-aprendizaje de la lectoescritura, como un proceso articulado, el de la revalorización de la cultura, como lo expresan los propios sujetos y el que remite a las habilidades en términos de herramientas que se construyen desde las escuelas en general.

“...El avance en la lectoescritura y en revalorización identidad cultural es importante, ambas cosas, paralelamente, se han ido logrando..." (ANTONIO. Referente de la comunidad. Encuentro colectivo "los significados de la educación intercultural". Registro de campo N³4. Septiembre, 2012 en MARTÍNEZ, 2014). 


\section{Referencias}

ACHILLI, E. Escuela, familia y desigualdad social. Una antropología en tiempos neoliberales. Rosario: Laborde, 2010.

BALAZOTE, A y RADOVICH, J.C. "Indígenas y fronteras. Los límites de la nacionalidad". En BALAZOTE, A y RADOVICH, JC. (comps) Estudios Antropológicos en la Argentina. Buenos Aires: Minerva, 1999.

GORDILLO, G y HIRSCH, S (Comps), Movilizaciones Indígenas e identidades en disputa en la Argentina. Buenos Aires: La Crujía. 2010.

GOROSITO KRAMER, A. M. "Identidad étnica y manipulación", en: Hídalgo \& Tamagno (comps.). Etnicidad e identidad. Buenos Aires: CEAL, 1992.

"Convenios y leyes: La retórica políticamente correcta del Estado" en Cuadernos de Antropología Social, Vol 28, pp.51-65, Buenos Aires. Diciembre 2008. Disponible en www.scielo.or.ar, Acceso: enero 2011. ISSN: 0327-3776.

GRECA, V. "Un proceso de rebelión indígena: los mocovíes de San Javier en 1904”. Avá [online]. 2009, n.15 [citado 2018-07-05], pp.00-00. Disponible en:<http://www.scielo.org.ar/scielo.or.ar. Acceso: noviembre 2012. ISSN 1851-1694.

GUALDIERI, B, "Apuntes sociolingüísticos sobre el Pueblo Mocoví de Santa Fe (Argentina)". BilingLatAm, pp119,129. Buenos Aires 2004. Disponible en http://www.yumpu.com/es/document/view/12424947/apuntes-sociolinguisticos-sobreel-pueblo-mocovi-de-essarp. Acceso: febrero 2012.

HECHT, AC. Educación intercultural bilingüe: de las políticas homogeneizadoras a las políticas focalizadas en la educación indígena argentina. Revista Interamericana de Educación de Adultos [en linea] 2007, 29 [Fecha de consulta: 5 de julio de 2018] Disponible en: <http://www.redalyc.org/articulo.oa?id=457545100003> ISSN 01888838.

ESCOLAR, D. Los dones étnicos de la Nación. Identidades huarpe y modos de producción de Soberanía en Argentina. Buenos Aires: Prometeo, 2007.

MARTÍNEZ, M. E. (2014) Políticas educativas y diversidad sociocultural. Un análisis socioantropológico sobre la construcción de políticas y prácticas educativas acerca de la atención a la diversidad. Tesis doctoral en Humanidades y Artes. Mención Antropología. Facultad de Humanidades y Artes. UNR, Rosario, MIMEO.

RINGUELET, R. "Etnicidad y Clases Sociales". En Hidalgo y Tamgno (comps). Etnicidad e Identidad. Buenos Aires: Centro Editor de América Latina, 1992.

VÁZQUEZ, H. Procesos identitarios y exclusión sociocultural. La cuestión indígena en la Argentina. Buenos Aires: Biblos, 2000. 


\section{Notas de campo:}

Registro de campo №31. Entrevista Antonio, miembro de la comunidad Mocoví. Agosto del 2011.

Registro de campo N³4. Ignacio. Miembro de la comunidad. Encuentro colectivo "los significados de la educación intercultural" junto a jóvenes y miembros del consejo de idioma y cultura. Septiembre, 2012.

Registro de campo No34.Antonio. Referente de la comunidad. Encuentro colectivo "los significados de la educación intercultural" junto a jóvenes y miembros del consejo de idioma y cultura. Septiembre, 2012.

Registro de campo No 34. Nahuel. Miembro de la comunidad. Encuentro colectivo "Los significados de la educación intercultural”. Septiembre del 2012.

Registro de campo No 34 Sonia. Referente de la comunidad. Encuentro colectivo "Los significados de la educación intercultural”. Septiembre del 2012.

Registro de campo No 30. Observación participante. Abril 2010.

Registro de campo №27. Observación participante. Junio 2009.

Registro de campo. № 26. Observación participante. Mayo del 2009.

Registro de campo N²9. Entrevista Valeria. vice directivo Mayo del 2010.

\section{Notas}

${ }^{\mathrm{i}}$ ANTONIO. Referente de la comunidad. Registro de campo №31. Entrevista Agosto.2011 en MARTíNEZ, 2014, pp. 245 .

ii “...Trabajar junto a las organizaciones comunitarias en la concreción, a mediano plazo del funcionamiento de una escuela secundaria en la zona; En la tarea preventiva de enfermedades endémicas de la zona, como campañas de vacunación, organización de charlas médicas, funcionamiento del dispensario, organización y planificación familiar; Visitas y charlas de instituciones como U.N.T.A, M.A.G.I.C, para la organización y optimización de los trabajos rurales en la zona, aprovechamiento e industrialización de productos de quintas, micro emprendimientos, etc.; Concreción de la red de agua potable, construcción de viviendas, sanitarios, pozos para la extracción de agua, contaminación ambiental, combatiendo roedores, insectos que son fuente de enfermedades en la comunidad..." (PROYECTO ESCUELA BILINGÜE. Comunidad Mocoví de Recreo. Escuela Primaria Común Diurna S/R en MARTÍNEZ, 2014, pp.200).

iii Una versión preliminar fue presentada en MARTÍNEZ, M. E; VILLAREAL, MC; GRECA, V y VERA, R. (2012) "Los usos de la interculturalidad. La Educación Intercultural Bilingüe en la provincia de Santa Fe". Segundo Taller de Antropología y Educación. Antropología y Educación en Argentina. Tendencias y Desafíos actuales. 6, 7, y 8 de junio del 2012. CEACU, Rosario, Facultad de Humanidades y Artes. UNR.

iv ANTONIO. Referente de la comunidad. Registro de campo $N^{\circ}$ 30. Observación participante. Abril 2010.En MARTÍNEZ, 2014, pp.200. 


\section{Sobre la autora}

María Eugenia Martínez. Doctora en Humanidades y Artes con mención en Antropología y Licenciada en Antropología Sociocultural. Es JTP dedicación simple, ordinaria en las cátedras de Antropología y de Teoría Sociológica II en FHUCUNL. Becaria de CONICET (2007-2012) Integra dos $\mathrm{CAI}+\mathrm{D}$ relacionados a las prácticas educativas de innovación que promueven el pensamiento crítico y sobre la polarización social y política en Argentina, en la mencionada institución. Docente interina en las materias de Problemátias Antropológicas y Sociológicas y Antropología Sociocultural en Institutos de Formación Docente de Santa Fe. Correo electrónico: eugemartis@gmail.com

Recebido: 10.06 .18

Aprovado: 28.06.18 